\title{
EDITORIAL
}

\section{In 2035, will all bacteria be multidrug resistant? We are not sure}

\author{
Kevin B. Laupland ${ }^{1 *} \mathbb{D}$, Etienne Ruppé ${ }^{2}$ and Stephan Harbarth ${ }^{3}$
}

(C) 2016 Springer-Verlag Berlin Heidelberg and ESICM

The development of antibiotics revolutionized the management of patients with infectious diseases and may be considered as a defining moment of modern medicine [1]. However, emergence of resistance to antimicrobials is challenging our practice by threatening to reverse decades of progress [2]. Patients with few or no effective antibiotic therapy options due to resistance are increasingly observed and the possibility exists that this will worsen to the point where in some countries or patient populations the antibiotic therapy era will become only of historical relevance over the next two decades [3]. Given the current situation, antibiotic resistance, especially among Gram-negative pathogens, will most likely continue to evolve with low-income countries at greatest risk [4]. We propose that following a continuous rise, resistance will reach an ultimate point where the economic, medical, and social environment will change such that we will have the ability to continue to manage these important infections (Fig. 1).

As for the economy, the discovery and development of a range of new antibiotic agents may be expected on the basis of likely future incentives [5]. The ability of the pharmaceutical industry to develop new compounds to treat multidrug-resistant pathogens should not be underestimated. The current dearth of new antimicrobial agent discovery is likely at least in part a reflection of the high cost of development with limited return on investment rather than an exhaustion of the possibilities for novel therapies per se [6]. From an industry perspective, the reward for producing agents directed at chronic infections such as

\footnotetext{
*Correspondence: klaupland@gmail.com

1 Department of Medicine, Royal Inland Hospital, 311 Columba Street, Kamloops, BC V2C 2T1, Canada

Full author information is available at the end of the article
}

For contrasting viewpoints, please go to doi:10.1007/s00134-016-4310-y and doi:10.1007/s00134-016-4348-x.

\section{Springer \\ 伨 Springer}

HIV is potentially far greater as these patients will require lifelong therapy. This is even more so the case for noninfectious chronic diseases such as diabetes or heart disease that affect a sizable proportion (i.e., 5-10 \%) of adult populations of high-income countries. It is not surprising that the pharmaceutical industry has little motivation presently to develop antibiotic agents to treat a few patients per 1000 population annually with severe infections for 1-2 weeks of therapy. However, should the day come that all bacteria are multi- or even pan-drug resistant, economic realities will dramatically change as we would then likely be willing to pay for much more expensive therapies that would be effective for highly lethal but treatable infections such as meningitis or intra-abdominal infection. Exorbitant prices and de-linkage reimbursement models (e.g., financial benefit independent of the sales volume) for these future effective antibiotics would likely preclude their widespread use for nonsevere infections with a resultant reduction in the pressure on development of further resistance.

A second consideration with increasing resistance is that at some point we will be forced to think outside of the antibiotic "box". As a result of the remarkable success of antibiotics, until relatively recently we have not been highly motivated to consider alternative approaches. We have been complacent regarding source control, and research in this regard represents a miniscule fraction of therapeutic approaches [7]. We know that prompt drainage of skin abscesses can reduce antibiotic consumption considerably, yet it is likely that most patients are treated with antibiotics in actual practice [8]. We are only just starting to learn about alteration of our microbiota for the management of infectious diseases, and our knowledge and manipulation of microbial interactions and communication in biofilms remain limited [9]. Immune modulator or biotherapy was demonstrated to have a major therapeutic effect in the preantibiotic era, yet further advances have been limited over the past century [10]. Indeed, a wide range of other nonantibiotic approaches have also been investigated [11]. 


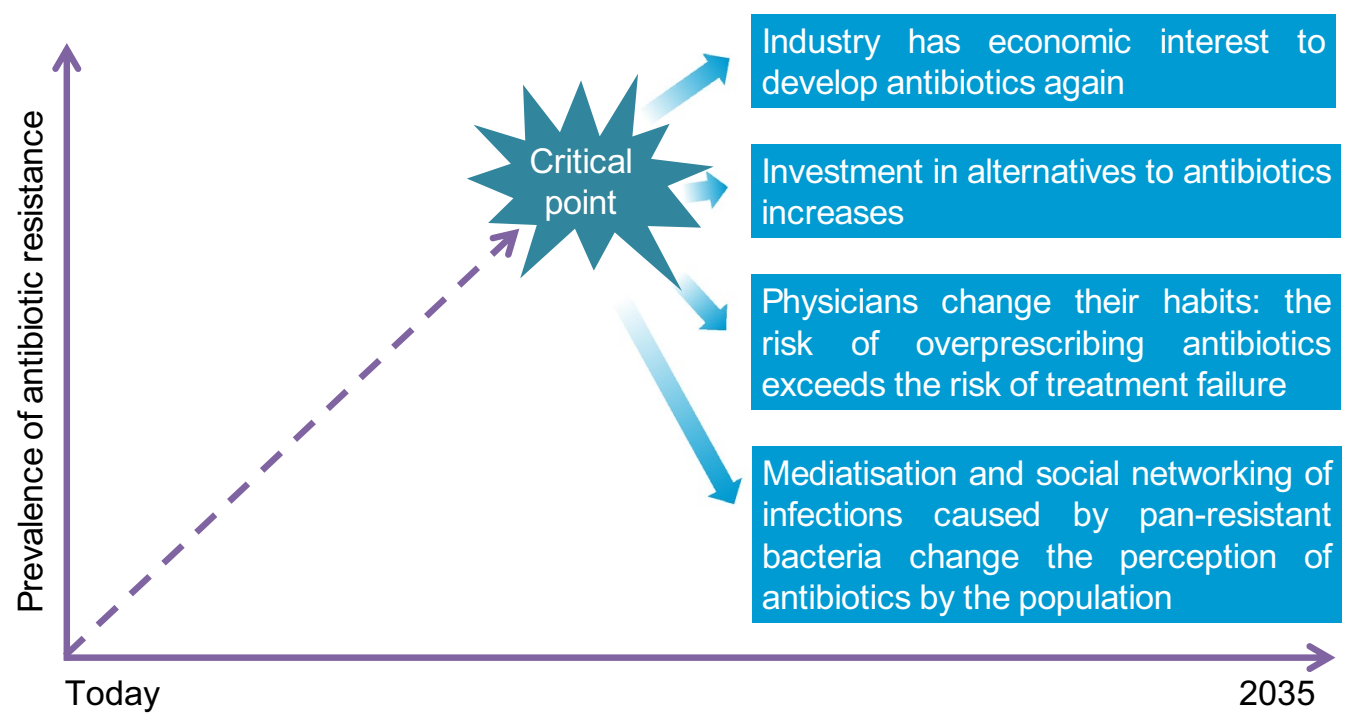

Fig. 1 Rise of antibiotic resistance up to a critical point where its perceptions by pharmaceutical industry, investors, physicians, and population will change

A third consideration that questions whether all bacteria will be multiresistant or at the very least that we will be able to manage them relates to the expected change in how antibiotics will be viewed by clinicians in the future. Physicians are generally aware of the risks of antibiotic therapy not limited to allergic reactions, toxicities, and risks for development of Clostridium difficile infection and resistance. However, presently overall these complications only become apparent in a minority of patients and thus are not strong deterrents to inappropriate prescription; therefore, a practice of prescription to be "on the safe side" is not uncommon [12]. However, should most or all bacteria become resistant in the future, we might frequently observe tragic deaths and morbidity as a result, even in young previously healthy individuals. Should this be the case then the culture of prescription of antimicrobial therapy will inevitably change, catalyzed by questions raised by media and the public. Take for example the inappropriate treatment of asymptomatic bacteriuria in nonpregnant adults. We know that inappropriate treatment in this setting increases the risk for future infections with increasingly resistant organisms [13]. Despite this knowledge this practice remains widespread today. However, should the prospect of developing an untreatable infection become a common complication in the future, it would seem unlikely that clinicians would be likely to offer such therapy "to be on the safe side".

Eventually and given this uncertainty regarding the prospective of resistance, we must think of strengthening our defense strategy in our hospital units. At the community level, immunization for bacterial infections may be further developed. Universal immunization programs for pneumococcal disease have not only resulted in major decreases of invasive infections across all ages in populations but have also been associated with decreases in resistance [14]. Enhanced immunization efforts for other bacterial diseases such as urosepsis caused by extended-spectrum beta-lactamase-producing Enterobacteriaceae may become equally as effective. The situation outside our hospitals is for now out of control and, once they have emerged, some resistance determinants such as CTX-M or NDM beta-lactamases have globally spread in the community setting, thereby creating an influx of resistant bugs to the hospitals. As for our aforementioned argument, we should maybe not wait to reach such a point where resistance will be overwhelming but should test and implement the most efficient solutions to control the irrepressible influx of resistant bugs in our units, namely the investment in infection prevention and control programs and faster diagnostic tools for anticipating resistance and keep the antibiotic pressure to a minimum.

In summary, the possibility does exist that resistance will at some point in the future reach a point where the crisis will be realized by both the medical community and the public. Should that be the case, the economics of drug development will change. Perhaps equally as important, the recognition of the problem of resistance by physicians, patients, and the media will result in a shift in expectations and behaviors that will lead to better utilization of the agents and preventative strategies that we 
already have. Will all bacteria be multidrug resistant in 2035? Maybe. But we will have the capacity and available tools to deal with it.

\section{Author details}

1 Department of Medicine, Royal Inland Hospital, 311 Columba Street, Kamloops, BC V2C 2T1, Canada. ${ }^{2}$ Genomic Research Laboratory, Hôpitaux Universitaires de Genève, Geneva, Switzerland. ${ }^{3}$ Infection Control Programme, Hôpitaux Universitaires de Genève, Geneva, Switzerland.

\section{Compliance with ethical standards}

\section{Conflicts of interest}

None of the authors have any conflicts of interest to declare that are relevant to this manuscript.

Received: 12 March 2016 Accepted: 23 March 2016

Published online: 18 April 2016

\section{References}

1. Davies J, Davies D (2010) Origins and evolution of antibiotic resistance. Microbiol Mol Biol Rev 74:417-433

2. Carlet J, Collignon P, Goldmann D, Goossens H, Gyssens IC, Harbarth S, Jarlier V, Levy SB, N'Doye B, Pittet D, Richtmann R, Seto WH, van der Meer JW, Voss A (2011) Society's failure to protect a precious resource: antibiotics. Lancet 378:369-371

3. Tabah A, Koulenti D, Laupland K, Misset B, Valles J, de Carvalho FB, Paiva JA, Cakar N, Ma X, Eggimann P, Antonelli M, Bonten MJ, Csomos A, Krueger WA, Mikstacki A, Lipman J, Depuydt P, Vesin A, Garrouste-Orgeas M, Zahar JR, Blot S, Carlet J, Brun-Buisson C, Martin C, Rello J, Dimopoulos G, Timsit JF (2012) Characteristics and determinants of outcome of hospitalacquired bloodstream infections in intensive care units: the EUROBACT International Cohort Study. Intensive Care Med 38:1930-1945
4. Woerther PL, Burdet C, Chachaty E, Andremont A (2013) Trends in human fecal carriage of extended-spectrum beta-lactamases in the community: toward the globalization of CTX-M. Clin Microbiol Rev 26:744-758

5. Bettiol E, Harbarth S (2015) Development of new antibiotics: taking off finally? Swiss Med Wkly 145:w14167

6. Spellberg B, Bartlett J, Wunderink R, Gilbert DN (2015) Novel approaches are needed to develop tomorrow's antibacterial therapies. Am J Respir Crit Care Med 191:135-140

7. Eckmann C (2016) The importance of source control in the management of severe skin and soft tissue infections. Curr Opin Infect Dis 29:139-144

8. Liu C, Bayer A, Cosgrove SE, Daum RS, Fridkin SK, Gorwitz RJ, Kaplan SL, Karchmer AW, Levine DP, Murray BE, Rybak MJ, Talan DA, Chambers HF, Infectious Diseases Society of America (2011) Clinical practice guidelines by the Infectious Diseases Society of America for the treatment of methicillin-resistant Staphylococcus aureus infections in adults and children. Clin Infect Dis 52:e18-e55

9. Peters BM, Jabra-Rizk MA, O'May GA, Costerton JW, Shirtliff ME (2012) Polymicrobial interactions: impact on pathogenesis and human disease. Clin Microbiol Rev 25:193-213

10. Belk WP (1935) The specific treatment of lobar pneumonia. A statistical review. JAMA 105:868-871

11. Czaplewski L, Bax R, Clokie M, Dawson M, Fairhead H, Fischetti VA, Foster S, Gilmore BF, Hancock RE, Harper D, Henderson IR, Hilpert K, Jones BV, Kadioglu A, Knowles D, Olafsdottir S, Payne D, Projan S, Shaunak S, Silverman J, Thomas CM, Trust TJ, Warn P, Rex JH (2016) Alternatives to antibiotics - a pipeline portfolio review. Lancet Infect Dis 16:239-251

12. Velasco E, Espelage W, Faber M, Noll I, Ziegelmann A, Krause G, Eckmanns $\mathrm{T}$ (2011) A national cross-sectional study on socio-behavioural factors that influence physicians' decisions to begin antimicrobial therapy. Infection 39:289-297

13. Cai T, Nesi G, Mazzoli S, Meacci F, Lanzafame P, Caciagli P, Mereu L, Tateo S, Malossini G, Selli C, Bartoletti R (2015) Asymptomatic bacteriuria treatment is associated with a higher prevalence of antibiotic resistant strains in women with urinary tract infections. Clin Infect Dis 61:1655-1661

14. von Gottberg A, de Gouveia L, Tempia S, Quan V, Meiring S, von Mollendorf C, Madhi SA, Zell ER, Verani JR, O'Brien KL, Whitney CG, Klugman KP, Cohen C, GERMS-SA Investigators (2014) Effects of vaccination on invasive pneumococcal disease in South Africa. N Engl J Med 371:1889-1899 